\title{
An Investigation Of Institutional Enhancement Factors On Student College Success
}

\author{
Amaechi Nkemakolem Nwaokoro, Ph.D., Albany State University, USA
}

\begin{abstract}
This study focuses on the importance of student's hard work and institutional factors - technology, advising, mentoring, and tutoring on student's academic performance. It is important for institutions to emphasize both student's hard work and effective institutional factors that will have positive impact on student success.
\end{abstract}

Keywords: Academic Performance; Mentoring; Students' hard-work, Instructional Technology; Advising; Learning improvement, Learning Community

\section{INTRODUCTION}

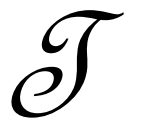

ime is scarce and waits for no one. Given this, a learning centered community could enhance student academic achievement by highlighting the importance of the student's hard work measured by the amount of time a student spends on academic activities outside of classroom. This time factor could make college experience become more challenging. For this reason, a learning centered community could integrate a learning process based on hard work and from student's non-academic activities. This inclusive integral community could instigate a time consciousness environment where students would be the winners.

Kamuche (2005) expresses that those students who are not well-exposed to adequate institutional enhancement skills are likely to change majors, make transfers, and even drop out of school. The costs of the resultant student failure are stated to be substantial. According to Albany State University (ASU) President, (Freeman, Jan. 2007), ASU retention rate is ranked second highest among the University System of Georgia and is ranked fourth within the entire Georgia University System. This is attributed to hard work of the university employees. The progress could keep on improving if freshman students are encouraged to articulate the principles of hard work and are required to interact with institutional enhancement factors.

Recognizing the importance of hard work and productivity success when his automobile company was at its infancy, Henry Ford in 1914 doubled his wages to as high as $\$ 5.00$ a day in a situation that was characterized by price cutting. To those who criticized this competitive wage/price policy, Ford clearly states,

"If you give all that, the money will fall into your hands, you cannot get out of it" (Gilder 1992, PP 194-196)

The wage/price strategy solicited hard work and affected the learning curve that created sizeable economies of scale. Both the firm's profit and net worth substantially increased. At the assembly line, the $\$ 5$ hard work wage was believed to have significantly reduced the workers' turnover. The "work hard" idea here can be extended to a learning centered community for students to relate grade success to hard work.

Given the revolutionary impact of technology in industrial establishments (Barnett \& Schorsch 1983, pp. 13, 27, Hogan, 1983, pp. 6-7, 77, 80, 108-109), one could argue that college institutional technologies may enhance student's college success. Also, student advising, mentoring, and tutoring may be positively related to college 
success. The study would address institutional technology, advising, mentoring, and tutoring as success enhancements or success shifters. The study would also consider the inter-temporal effect of grade success on the current grade success. This effect would have that if hard work is able to explain grade success in the previous period, the success itself could explain a current grade success as the student gets motivated. The critical issue that will be explored is that hard work, success enhancements, inter-temporal grade effect, and intervening factors may enhance college success in a learning-entered community. Having said this, the goals of the study are:

- $\quad$ to investigate the impact of student's hard work on college success, measured by grade point average

- $\quad$ to investigate the impact of technology and advising on college success

- $\quad$ to investigate the impact of student's mentoring and tutoring on college success

In any endeavor, hard work is usually the key that explains success outcome and this could also explain high grade success. This study, therefore, relates grade performance success to hard work measured by time a student spent on independent study. The following is the remainder of the study. In section II the study reviews literature. Section III presents the demographic characteristics of the target population. Section IV centers discussion on research methodology, data and measurement issues. Respectively, sections V and VI center on results, and conclusion and future study. I will relate this research to success outcomes discussion in Kamuche (2005), Gilder 1992, and Golub (1995).

\section{REVIEW OF LITERATURE}

Like in any other endeavor, student's educational success could depend on the number of hours the student is willing to invest in independent study (study outside the classroom). Every aspect of a lecture may not be understood in the classrooms. Difficult lessons, most especially, would require a substantial amount of time spent on studying and doing the related assignments. This goes to explain that practice makes perfect. With all the efficiency of classroom teaching, college success may not improve if students do not spend adequate time to independent study. As the time (a measure of hard work) increases, the associated benefit — grade improvement could take place. It goes to address the issue that if we believe that education is a learning process; hard work measured by time has to be a part of the process. People usually attribute success to endurance, persistence, and time observed. Educational process is not an exception to this golden rule. Therefore students would have to spend a reasonable amount of time in their study for college experience to relate to the desires of their intended professions.

Without the presence of hard work, other measures that would facilitate success may be ineffective. After a teacher has engaged in an effective teaching, a student who invests an immediate time period to the issues covered would be most likely to have a meaningful college experience. It is a convention that a student should not have more than a day's delay before revisiting current lectures.

Technology could have a significant impact on student success. The question is how much does it have? The 1970s and 1980s did not witness a significant spread of college success enhancement technologies. Academic success then depended for the most part on hard work. Most quantitative results were manually calculated. Now that success enhancement technologies are available, students need be encouraged to take advantage of them to enhance their academic success. Kamuche (2005) indicates that about 13\% of the tested sample has employed performance enhancement skills in their study. While working on SACS reaffirmation at Albany State University, the Quality Enhancement Plan "QEP" committee identified from a survey, technology and advising to be critical institutional factors that the university community would want to address (Johnson, Dec. 2006).

With all the efficiency of classroom teaching, college success may not improve if students do no spend adequate time to learn and to relate theories and issues to technologies. Miller et al (2005) expressed campus computer services technology as the mostly used resource by students. It would behold the faculty and administration to install and to instruct the relevant technologies like Web CT for on-line course taking. The most relevant technologies could therefore be part of an evolutionary and elevating curriculum and programs. Technologies may be conveniently situated for easy access. Instructional technology experts may need to be readily available. The students must be able to see the relationship between the particular technologies and the expected success benefits. Given this, it could be reasoned that 
college success experience would include the impact of state of the art technology.

Advising is also often highlighted as a critical factor for sequential course taking and for relating programs to the demands of professions. With proper advising, students could even take interdisciplinary courses that would enhance their comparative advantage in their chosen professions. Advising on applicable internships could lead students to make transitional movement towards where success is an outcome. Student success could improve if students are well advised on time management that could lead to proper time allocation in college activities. This could lead the target population to develop the foresight needed for success. A student that is able to manage his time would reap an exciting success.

Student mentoring is another variable that could impact college success. Students would be ethical where advisors are ethical. Success related attributes and traits could show students the opportunities available by embracing these issues. Mentoring could start right from the day the students set their feet on a campus.

Recognizing that students have different socio- and ethnical and educational backgrounds, the importance of mentoring may not be overemphasized. Students could appreciate role models that may be lacking in their families and communities. There could be a need to compliment students when it is warranted and to give constructive criticism if necessary. "Can do attitude" may relate mentors with students. This positive reinforcement would enable students to grow up with critical thinking skills to articulate orally, quantitatively, and qualitatively. These would give rise to student intellectual engagement. Gaither, George, A, Darrell L. Butler (2005) respectively highlights application, research, and critical thinking as skills that students in psychology expect to achieve. These skills rank higher than communication and technology skills. Student articulation could improve by applying to the readings in LAST, GRE, and GMAT. Other success enhancements could be exposure to theories on: test taking, note taking, listening, and talking skills.

Tutoring at any level would improve grade success. Since students come to a learning community with different socio- economic and educational-ethnic backgrounds, it could be important for them to have differential treatments. Tutoring may have to recognize the treatments at extensive and intensive levels for each individual student. Given this a service teacher would receive a feedback from students and would therefore intervene by moderating or improving the tutoring. Tutoring could give a student the last chance to have explanations to issues missed during instruction. Attending to tutorial also requires the student's time which would beef-up the hard work of the student. After the tutorial, a student who takes time to revisit the issues explained would stand at a better chance of maximizing grade success at a higher level. Students would agree that tutoring boosts grade success and also takes a lot of time which is a measure of hard work that is the bedrock of college success.

With peer tutoring, students could see explanations from the perspectives of the peers. This interaction could create group dynamics which would lead to detailed explanations to questions and issues. Peer tutoring could be very effective where questions require defined procedures leading to quantitative results.

Other than the aforementioned factors, knowing and installing other college resources that would enhance student college-experience would also need some priority. These resources would include but not limited to library and some other common public resources.

Although not measured here and would therefore be left for future study, intervention factors could be very necessary for student success. Academic early warning red flag may need to be raised when students are not doing well or are about to get in to a probationary status. The students at this rank must be called in, advised and encouraged to improve on their status. Also they could be sent to any learning center or counselor where additional help is accessible. Where eventually students are not doing well or are unable to improve, they could be withdrawn from college while recommending alternative endeavors. During freshman orientation, all the students' expectations must be well addressed. Students must ask questions and be asked the relevant questions.

Also, there must be early intervention to prevent student indebtedness from student loans. Growing indebtedness could be a source of frustration, most especially when a student is not making the expected progress. Loan acquisition may have to be the last option when a student puts a financial aid package together. They may have to watch 
video coverage about what loaning is really supposed to address. Loaning may be exercised only when other funding areas have been exhausted. Grants and loans may be tied to hard work that leads to academic performance. Funding could cease when GPA falls below a well-defined critical point and this must be clearly communicated to students. Every student's academic reward could depend on academic performance leading to student college success.

\section{DEMOGRAPHIC CHARACTERISTICS OF THE TARGET POPULATION}

This exploratory study addresses freshman's college educational success. The majority (traditional students) in target population may have left home for the first time for the pursuit of self-development. Particularly, this segment of the population may not articulate well enough the scarcity of their college time and of other resources in general. Also, these students' college experience is likely to come mostly from non-academic activities. Bad grades are likely to be recorded during freshman years "non-challenging period". This could call for a vital need to have in place, the importance of hard work, and critical success enhancement factors--technology, advising, mentoring, and intervening factors. These enhancement factors are articulated as success shifters.

If any particular group is expected to be excited about technologies, the target group here is supposed to be the one. This is the group of students that were born in the era of technology. This audience is likely to use some kinds of technologies to play games or to use Internet for various reasons. Therefore this study would expect strong positive relationships between student appreciation for enhancement technologies and excellent learning-outcomes. ASU, where the sampling would take place is liberal arts, and co-educational institutions. Both male and female students would be in the target audience.

\section{RESEARCH METHODOLOGY, DATA AND MEASUREMENT ISSUES}

Conceptually, since hard work (time, (T)), technology (tech), advising (Ad), mentoring (Mn), and Tutoring $(\mathrm{Tu})$ could enhance grade point average (GPA), grade point average equation can be generally stated as:

$\mathrm{GPA}_{\mathrm{t}}=f(\mathrm{~T}, \mathrm{Tech}, \mathrm{Ad}, \mathrm{Mn}, \mathrm{Tu})$.

Equation (1) shows the direct impact of the exogenous variables. These variables were generated from junior-standing classes at Albany State University. These classes are credible and appropriate testifiers of the freshman-experience. GPA variable is a student's cumulative grade points divided by the number of courses and this is usually calculated at the ends of sophomore and senior years.

The hard work (time factor) is the student's average weekly hours spent on independent study. For a fulltime student taking a weekly course load of 13-15 credit hours (normal load), at least this range of hours may have to be observed by the full time student on an independent study basis. From this range of hours, the interval's mark is taken as fourteen $((13+15) / 2)$. This would indicate that a student who applies 14 hours or above on an independent study is most likely to have a successful college experience.

Technology, advisement, mentoring, and tutoring are considered as success enhancement factors or shifters. Each variable was constructed by assigning various point-value ranges out of which the mark of the range is taken and it describes an average student's appreciation for the use of the particular variable. Similarly, the GPA was constructed from the assigned grade point average ranges. The descriptive statistics of the variables are presented in Table 1.

Empirical analysis of mean of grade point average relative to the mean of each of the explanatory variables are $(0.56,0.85,1.19,1.42,1.39)$ respectively. The ratio of grade point average to hard work $(0.56)$ indicates that if the mean of hard work improves by one additional level, the mean of the grade point average would improve by 0.56 with other variables remaining constant. Each of the rest of the values can be interpreted as improvement of mean of grade point average relative to the additional effect from the mean from the respective explanatory factor. With the presence of large standard deviations of the means, the enhancement factors do not seem to have appreciable effect on success. 
Table 1: Summary statistics

\begin{tabular}{|l|c|c|}
\hline \multicolumn{1}{|c|}{ Variable Name } & Mean & Standard Deviation \\
\hline GPA & 3.051 & 0.392 \\
\hline Weekly Independent Study Hours & 5.475 & 2.838 \\
\hline Technology Preference & 3.571 & 0.974 \\
\hline Advising Preference & 2.560 & 1.130 \\
\hline Mentoring Preference & 2.151 & 1.143 \\
\hline Tutoring Preference & 2.200 & 1.100 \\
\hline Observations: 220 & & \\
\hline
\end{tabular}

Figure 1 also highlights the apparent relationship between success enhancement factors and grade point average. Cautiously speaking, the grade point average seems to be driven by the enhancement factors.

Figure 1: Summary Bar Graphs

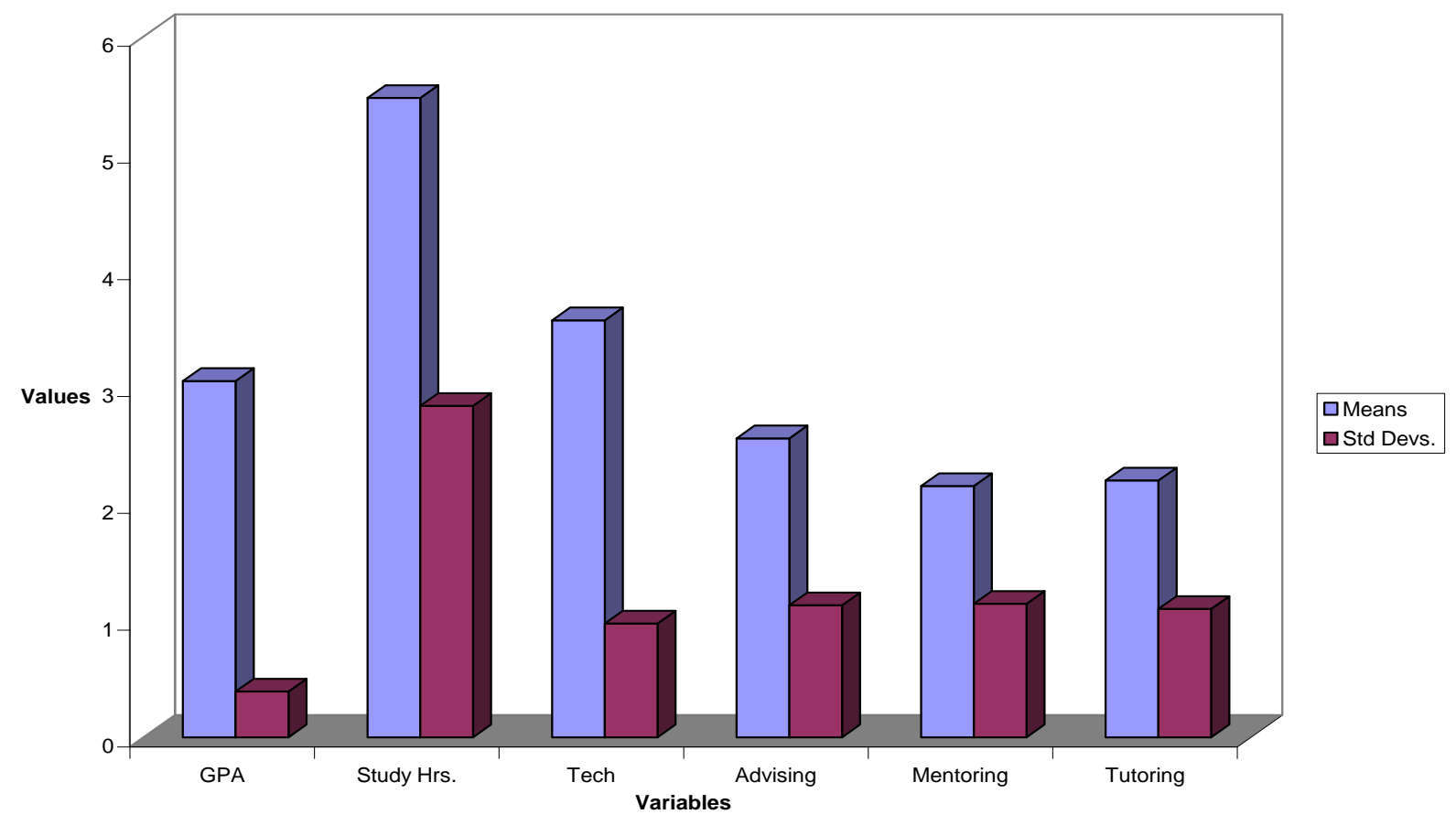

Specifically, it is apparent that only technology as a success deterministic factor is associated with a smaller value of standard deviation than do other enhancement factors. This would imply that technology could have an appreciable impact on college success if adequately articulated. As students get to relate course disciplines to this enhancement factor, the factor could become more important.

\section{RESULT}

Since the enhancement factors do not seem to have significant effect on success, poor student performance could be explained by inability to understand the applicability of the innovative factors. This calls for innovative ways for communicating the factors to the students. Enhancement technologies need to be instructed for student to be able to apply appropriate technologies to the requirements of courses. Different socio- ethnic and educational backgrounds could be getting on the way and prevents mentoring from having appreciable impact on grade success. It is therefore important to have appropriate mentoring. 


\section{CONCLUSION AND FUTURE STUDY}

The study does not find strong relationships between the explanatory variables and grade success. This implies that students do not understand the relevance of the factors. Given this, students may not be able to use technologies to construct measurements, estimates or graphical forms that are the basis for extended empirical analysis. These are ways to empirically and graphically highlight course contents. Applicable technologies may need to be instructed to students from a freshman course. By embracing these technologies at this level, they would become more comfortable with their application. Ill-advisement could be getting on the way of innovative performance. Students may not be taking courses sequentially and this could lead to inadequate performance.

The study compliments Albany State University QEP committee's request for relevant technology and meaningful student advising that are expected to facilitate student learning. Given this, this study would suggest that Title III funds (funds provided by Federal government to Historically Black Colleges and Universities (HBCU) for strategic planning and for implementing the issues that facilitate the learning of people of color) should aim mostly at updating technology and training in the use of technology at ASU. These could have an appreciable effect on Individualized Academic Development Plan (IADP) that is being emphasized so that no child is academically left behind. Different socio-economic and ethnic educational backgrounds could be getting on the way and preventing mentoring from having appreciable impact on grade success. With tutoring not having appreciative effect on grade success, it could imply that the students do not understand course contents. It is therefore important to have appropriate enhancement factors and mandatory training sessions for their discussion. I am yet to observe this kind of session at Albany State University.

The study would also advise future scholars to empirically estimate the impact of the enhancement factors, and of group dynamics on student success. Appropriate interaction in a group could lead to improvement on student success. The impact of student/faculty ratio, student class participation, test taking, note taking, listening, and talking skills on student academic achievement would also be worth investigating.

\section{AUTHOR INFORMATION}

Dr. Amaechi N. Nwaokoro is an Assistant Professor of Economics at Albany State University, Albany, Georgia. He earned a doctorate in economics from University of Oklahoma, a Masters of Business Administration from Oklahoma City University, and a bachelor degree in Business \& Economics from Northwestern Oklahoma State University. Dr. Nwaokoro has published half- a- dozen refereed journal articles and some conference proceedings. $\mathrm{He}$ is currently researching and writing manuscripts for publication. He has over ten years of continuous teaching experience at both undergraduate and graduate levels of economic education.

As a member of Southwestern Social Science Association, I review articles for Southwestern Journal of Economics, an affiliate of the Association. I have made various professional presentations during the meetings of this association.

Economics is my passion and I also enjoy traveling. I derive joy doing charity work. This is another call that also requires my time here on earth. For more details about my background, research interests, publications, and work experience request for my full resume. Dr. Nwaokoro can be reached at 229-430-4723 or e-mail: Amaechi.nwaokoro@asurams.edu

\section{REFERENCES}

1. Barnett, Donald F., and Louis Schorsch, 1983. Steel: Upheaveal in a Basic Industry. Ballinger Publishing Company. Cambridge, Massachusetts.

2. Freeman, Everette J., Jan. 26, 2007. "ASU is Among the Best in the State at Retaining and Graduating Students". ASU Info, Albany State University.

3. Gaither, George, A, Darrell L. Butler 2005. "Skill Development in The Psychology Major: What Do Undergraduate Students Expect?” College Student Journal, 3:540-552.

4. Gilder, George, 1992. Recapturing the Spirit of Enterprise, ICS Press, San Francisco, California. 
5. Golub, Stephen, 1995. "Productivity and Labor Cost in Newly Industrialized Countries". FRBSF Weekly Letter, Federal Reserve Bank of San Francisco.

6. Hogan, William T. 1983. World Steel in the 1980s: A Case of Survival. Lexington Books, D.C. Heath and Company. Lexington, Massachusetts.

7. Johnson, Joyce, Dec. 4, 2006. “Quality Enhancement Plan”. Quality Enhancement Plan Committee, Albany State University.

8. Kamuche, Felix U. 2005. "Student Perceptions of Two State Universities in Texas: A Comparative Analysis". College Student Journal, 3:411-434.

9. Miller, T. Michael, Myron L. Pope, Thomas D. Steinmann, 2005. "A Profile of Contemporary Community College Student Involvement, Technology Use, and Reliance on Selected College Life Skills”. College Student Journal, 3:596-603. 


\section{NOTES}

